\title{
Prevalence, patterns and factors associated with hypertensive crises in Mulago hospital emergency department; a cross-sectional study
}

\author{
Irene Nakalema ${ }^{1}$, Mark Kaddumukasa ${ }^{1}$, Jane Nakibuuka², Emmy Okello ${ }^{3}$, Martha Sajatovic ${ }^{4}$, Elly Katabira ${ }^{1}$
}

1. Department of Medicine, College of Health Sciences Makerere University, P. O. Box 7072 Kampala, Uganda. 2.Mulago National Referral and Teaching Hospital, P.O Box 7051 Kampala, Uganda.

3. Uganda Heart Institute, Mulago National Referral and Teaching Hospital, P. O. Box 7051 Kampala, Uganda.

4. Neurological and Behavioral Outcome Center, University Hospitals, Case Western Reserve University.

\section{Emails}

Irene Nakalema - nakalemairene14@gmail.com, Mark Kaddumukasa - kaddumark@yahoo.co.uk, Jane Nakibuuka -Nakibuukajm@yahoo.com, Emmy Okello-emmkol@hotmail.com, Martha Sajatovic- Martha.Sajatovic@UHhospitals.org, Elly Katabira -katabira@imul.com

\begin{abstract}
Background: Hypertension is increasing in sub-Saharan Africa (SSA) and it's the single most important modifiable stroke risk factor, yet it's control is not routinely emphasized.

The prevalence, pattern and factors associated with hypertensive urgencies and emergencies in Uganda is not well established. A cross-sectional study, was conducted between November 2015 and February 2016, using a complete clinical examination and pre-tested standardized questionnaire subjects were enrolled. The prevalence of hypertensive crises and associations of demographic and clinical factors determined using logistic regression.

Results: The prevalence of hypertensive crises was 5.1\%, (203/4000) of all admissions at the medical section of the accident and emergency ward of Mulago National Referral Hospital. The hypertensive urgencies and emergencies accounted for 32.5\% and $67.5 \%$ respectively among study subjects with hypertension. Among those with hypertensive crises, 41.1\% were aged 45-65 years and half were female. Self-reported compliance was significantly different between those with hypertensive crisis compared to non-hypertensive crisis with OR; (95\% CI) 52.4; (24.5 - 111.7), p-value $=<0.001$. Acute stroke was the commonest hypertensive emergency.

Conclusion: Hypertensive emergencies are common and significantly associated with poor compliance to prescribed anti-hypertensive drugs. Acute stroke is the commonest presentation in our setting.

Keywords: Hypertensive crises, prevalence, factors associated.

DOI: https://dx.doi.org/10.4314/ahs.v19i1.52

Cite as: Nakalema I, Kaddumukasa M, Nakibunka J, Okello E, Sajatovic M, E K. Prevalence, patterns and factors associated with hypertensive crises in Mulago hospital emergency department; a cross-sectional study. Afri Health Sci. 2019;19(1). 1757-1767. https:// dx.doi. org/10.4314/ ahs. v19i1.52
\end{abstract}

\section{Background}

Cardiovascular diseases (CVDs) remain the leading cause of death and disability in the world with over $80 \%$ of

\section{Corresponding author:}

Mark Kaddumukasa,

Department of Medicine,

College of Health Sciences Makerere University,

P. O. Box 7072 Kampala, Uganda

Email:kaddumark@yahoo.co.uk
CVD deaths occurring in low- and middle-income countries. Majority of these CVD deaths occur in individuals aged less than 60 years in these countries ${ }^{1,2}$. Hypertension is the single most important modifiable stroke risk factor as well as other associated complications, yet it's control is not routinely emphasized ${ }^{3}$. About 75 million people with hypertension live in sub-Saharan Africa (SSA), with a projection that 125.5 million people in SSA will be affected by $2025^{4,5}$. Studies in SSA, both urban and rural communities show a high prevalence of $19.3 \%$ (95\% CI:17.3-21.3) in rural Nigeria, 21.4\% (19.8-23.0) in rural Kenya, 23.7\% 
(21.3-26.2) in urban Tanzania, and 38.0\% (35.9-40.1) in urban Namibia. ${ }^{6}$ Uganda WHO-STEPS data evaluated a sample of 3987 household respondents aged 18-69 years old and found that $24.3 \%$ were regarded as having raised blood pressure (BP). Raised BP was more prevalent among males $(25.8 \%)$ than females $(22.9 \%)$ while occurring in $25.5 \%$ among urban compared to $24.4 \%$ in the rural settings ${ }^{22}$.

Elevations in blood pressure are classified by the eighth Joint National Committee, ${ }^{23}$ are classified as "hypertensive emergencies" in the presence of acute or ongoing end-organ damage or as "hypertensive urgencies" in the absence of target-organ involvement. Distinguishing hypertensive urgencies from emergencies is important in formulating a therapeutic plan. In the former the goal is to reduce blood pressure within 24 hours, whereas in the latter it is to lower blood pressure immediately (not necessarily to normal ranges) to prevent or limit target organ disease ${ }^{10-12}$. We set out to evaluate the prevalence, patterns of presentation and factors associated with hypertensive emergencies and urgencies in our setting. This knowledge will inform and guide decision on preventing, identifying hypertensive emergencies and target organ damage.

\section{Materials and methods \\ Study design}

This was a cross-sectional study conducted at Mulago National Referral and Teaching Hospital for Makerere University from $19^{\text {th }}$ November 2015 to $29^{\text {th }}$ February 2016.

\section{Study setting}

The study was carried out at Mulago National Referral and Teaching Hospital for Makerere University, College of Health Sciences. It is located about $3 \mathrm{~km}$ from Kampala, the capital city of Uganda. It has a bed capacity of 1500 beds and has both in-patient wards and out-patient departments for medical and surgical specialties. It has a radiology department with computerized tomography (CT) scan and highly trained personnel as well-as an equipped laboratory. The study participants were adults attending the medical side of the Accident and Emergency (A/E) unit; it has a bed capacity of about 55 beds and serves as an entry point for admitting adult medical patients. These are patients from Kampala metropolitan and referrals' from the entire country. All patients are triaged, resuscitated and are discharged or admitted to sub-specialist medical wards depending on their respective attendant problems.

\section{Study participants}

The study participants were adults attending the medical side of the accident and emergency unit; with elevated blood pressure $>140 / 90 \mathrm{mmHg}$. Patients with hypertension $(\mathrm{BP}>/=140 / 90)$, who presented with attendant problems and examination findings that were suggestive of possible target organ. Study participants were screened and enrolled; if they provided written informed consent and met the study inclusion criteria. Inclusion criteria included; those age above 18 years and provision of written informed consent. We excluded only participants who were unwilling to participate in the study.

\section{Sample size estimation}

The sample size for primary objective one was calculated using the Kish and Leslie formula, a standard formula for cross-sectional studies. Using prevalence of $27.5 \%$ for hypertensive crises among medical emergencies and urgencies, from an observation study done at a clinical emergency unit of an Italian referral hospital, ${ }^{25}$ we estimated a sample size of 306 participants.

Using case control study done among a minority population by Steven Shea ${ }^{24}$, found several factors associated with hypertensive emergencies including, lack of primary care physician, non-compliance to prescribed anti-hypertensive drugs, presence of alcohol related problems, we used these to approximate the sample size of associated factors and calculated a sample size of 90 participants. These participants were recruited consecutively until the desired sample size was attained.

\section{Study procedures}

Data was collected using an interviewer administered questionnaire. The caregivers'/study participants who presented at the $\mathrm{A} / \mathrm{E}$ department were informed about the study, its importance and its objectives and were screened for eligibility. Written informed consent was sought before enrollment into the study. For all hypertensive; those whose Blood pressure was $=/>140 / 90$ $\mathrm{mmHg}$, a focused history assessing the following factors was done: socio-demographics: age, gender, occupation, religion, level of education; medical history: history of 
$\mathrm{HT} / \mathrm{DM} /$ renal disease, alcohol use or smoking, iv drug use, access to care, compliance to drugs; clinical variables (attendant problems): impaired vision, headache, dizziness, chest pain, difficulty in breathing, reduced urine output, impaired cognitive function. A specific physical exam including waist and hip circumference, blood pressure and fundoscopy were done.

Waist and hip circumferences were used to obtain the waist-hip ratio. An abnormal waist/hip ratio for male was, ${ }^{3} 0.9$, and for female ${ }^{3} 0.85$ according to the Adult Treatment Panel III 13).

Two blood pressure readings were measured with the patient in the recumbent position by using a standard manual Dekametaccoson MK3 mercury sphygmomanometer machine, according to a standard technique. The average of the first and the second of two consecutive readings taken 5 minutes apart were used for analyses. Blood pressure was classified as according to the Seventh Report of the Joint National Committee on prevention, detection, evaluation, and treatment of high blood pressure as: 140 159/90-99mmHg - stage 1, 160-179/100-109mmHg - stage 2, > 180/110mmHg - stage $3^{10}$. Fundoscopy was performed using the Keeler head mounted indirect ophthalmoscope with 20D, on dilated pupils by study physician and a practicing ophthalmologist who counter checked findings. The findings of presence or absence bilateral linear or flame- shaped hemorrhages or "cotton wool" exudates with or without papilledema during funduscopic examination (grade III and IV hypertensive retinopathy, respectively, according to the Keith-Wagener and Barker classification were reported ${ }^{14}$. These findings in the setting of severe blood pressure elevation ( $>$ $180 / 110 \mathrm{mmHg}$ ) was considered hypertensive emergency with retinopathy.

Adherence to the prescribed regimen of blood-pressure medication was assessed with a five-item compliance scale derived from Morisky et al's the four-item scale. Minor changes in the wording of the four yes-no questions in the scale of Morisky et al, had been made by Shea et al. to make it a five- item scale ${ }^{24}$. The revised versions we used in this study read as follows;

Self-reported adherence to the currently prescribed reg- imen of blood-pressure medication was assessed with a set of questions below;

1. Do you ever forget to take your high-blood-pressure pills? Are you ever careless in taking your pills?

2. Do you ever miss taking your pills when you are feeling better?

3. Do you ever miss taking any of your pills because you are feeling sick?

4. Do you ever miss taking your high-blood-pressure medication for any reason?

We also scored 1 point for each positive response, so that a higher score indicated a lower level of compliance. A score of 3 or more positives was taken as poor adherence. Follow up for care was assessed in all participants with prior history of being hypertensive, the interview also included checking their hypertensive clinic medical cards or documents regarding how often participants returned for follow up reviews as scheduled on the card. This included 5(five) most recent scheduled dates. The response set was never $(0 / 5)$ for participants who never returned for review after initial diagnosis, sometime $(2 / 5)$ participants that returned at least twice of 5 scheduled dates, and often $(3 / 5)$ and always $(5 / 5)$ consecutively,this was done for participants that were attending the hypertensive, medical out-patient clinic at Mulago and had been hypertensive for at least one and half years. A score of more than three of the total of five visits $(>3 / 5)$ was taken as poor follow up with medical care.

For each participant, $3 \mathrm{ml}$ of blood were immediately transported in a clot activator tube to the clinical chemistry laboratory. The samples were stored on an ice pack and analyzed within 1 hour. Sample was analyzed by standard assay using an automated COBAS 600 machine to measure lipid profile: low density lipoproteins, high density lipoproteins, and total cholesterol; the cholesterols were abnormal if LDL was $>4.1 \mathrm{mlmol} / 1$, HDL $<0.9$ for male and HDL $<1.0$ for female. The classification of cholesterols was as per ATP III recommendations ${ }^{15,26}$.

Hypertensive patients who presented with attendant problems and examination findings that were suggestive of possible target organ. Specific investigations where 
done to assess for end-organ damage depending on patients' presentation. For neurological deficits -brain computerized tomography scans where done looking for acute hemorrhage, acute infarcts or normal. For reduced urine output-, urinalysis was done looking for dimorphic red blood cells or red blood cell casts. For chest pain or associated DIB- cardiac markers (Troponin T and CKMB) and ECG was done looking for ECG changes of myocardial infarction (ie T wave changes, ST segment elevation or depression). For difficulty in breathing and associated heart failure, chest X-Ray was done looking for features of pulmonary edema. Hypertensive crises included both emergencies and urgencies, were hypertensive emergencies was an elevated blood pressure with presence of acute target-organ damage while urgencies were defined as severe elevation of blood pressure of $>/=$ systolic of 180 and diastolic of $110 \mathrm{mmHg}$. The hypertensive emergencies diagnosed included; - Stroke (ischemic or intracerebral/subarachnoid hemorrhage) and were diagnosed based on clinical presentation and diagnostic investigations ${ }^{10}$. Acute glomerular nephritis was presumed in patients who presented with a history of having reduced urinary output volume in the past 7 days and confirmed with reduced urinary volume $<400 \mathrm{ml} / 24$ hours during admission and the presence of red blood cell casts or microscopic hematuria on routine urine microscopy. Acute coronary syndrome was confirmed with cardiac markers like troponin $\mathrm{T}$ and creatine kinase-iso-enzyme $\mathrm{MB}$ (CKMB) and electrocardiography (EKG) showing ST-elevation myocardial infarction (STEMI) of more than 0.1 $\mathrm{mV}$ in two corresponding leads, the non-ST elevation myocardial infarction (NSTEMI), considered as electrocardiographic ST-segment depression or prominent T-wave inversion and unstable angina pectoris (electrocardiographic ST depression or deep T wave inversion, with no elevation in troponin or creatine kinase-MB).

Acute pulmonary edema was confirmed by chest radiograph by findings of presence or absence bilateral heterogeneous opacities, diffuse with more concentration in the lung bases.

A standardized questionnaire was used to capture data collected from the interview, physical findings, and laboratory results of lipid profile, renal function tests, cardiac markers urinalysis; radiological investigations findings of chest x-ray and brain CT scan and electrocardiography findings.

\section{Statistical analysis}

Data was presented as mean $\pm \mathrm{SD}$ for the continuous variables while categorical variables were presented in frequencies and percentages. The prevalence of hypertensive crises was expressed as a percentage of the total number of patients admitted to the Medical A and E section of the Emergency Department during the study period. Factors associated with hypertensive crisis were determined using logistic regression, Odds ratio (with $95 \%$ confidence interval) was used as a measure for associations. Factors with p-values $<0.2$ at a bi-variable analysis were entered into a multiple logistic regression and model building done using likelihood ratio test to obtain adjusted estimates. Factors whose $95 \%$ confidence interval for the odds ratio that excludes a 1 or whose $\mathrm{p}$-value $<0.05$, were considered statistically significant. Analysis was performed with STATA 12.0. (StataCorp. 2011. Stata Statistical Software: Release 12. College Station, TX: StataCorp LP).

\section{Ethical aspects and subject protection}

Ethical approval was provided by the School of Medicine Research and Ethics Committee (SOMREC) Ref number: 2015-130 and Uganda National council of Science and Technology. Written informed consent was obtained from all the caregivers/study participants before enrolment into the study. Study participants diagnosed with hypertension or crises were treated according to the national treatment guidelines and appropriately referred for specialized care.

\section{Results}

A total of 4000 patients that presented to the medical section of the accident and emergency unit during the study period from November 2015 to February 2016 were screened. Out of the 4000 study participants, $7.5 \%$ (303/4000) were found to be hypertensive with a blood pressure more than $140 / 90 \mathrm{mmHg}$. Two hundred three study participants did meet the criteria of hypertensive crises, 67\% (203/303), 67.5\% (137/203) met the criteria for hypertensive urgency with BP more than 180/110 $\mathrm{mmHg}$ with no target organ damage. Thirty - two point five percent $(66 / 203)$ met the criteria of hypertensive emergency with elevated blood pressure 140/90 $\mathrm{mmHg}$ with associated target organ damage. The prevalence of hypertensive crisis was 5.1\% (203/4000) at accident and emergency department in Mulago hospital. See Figure 1. 


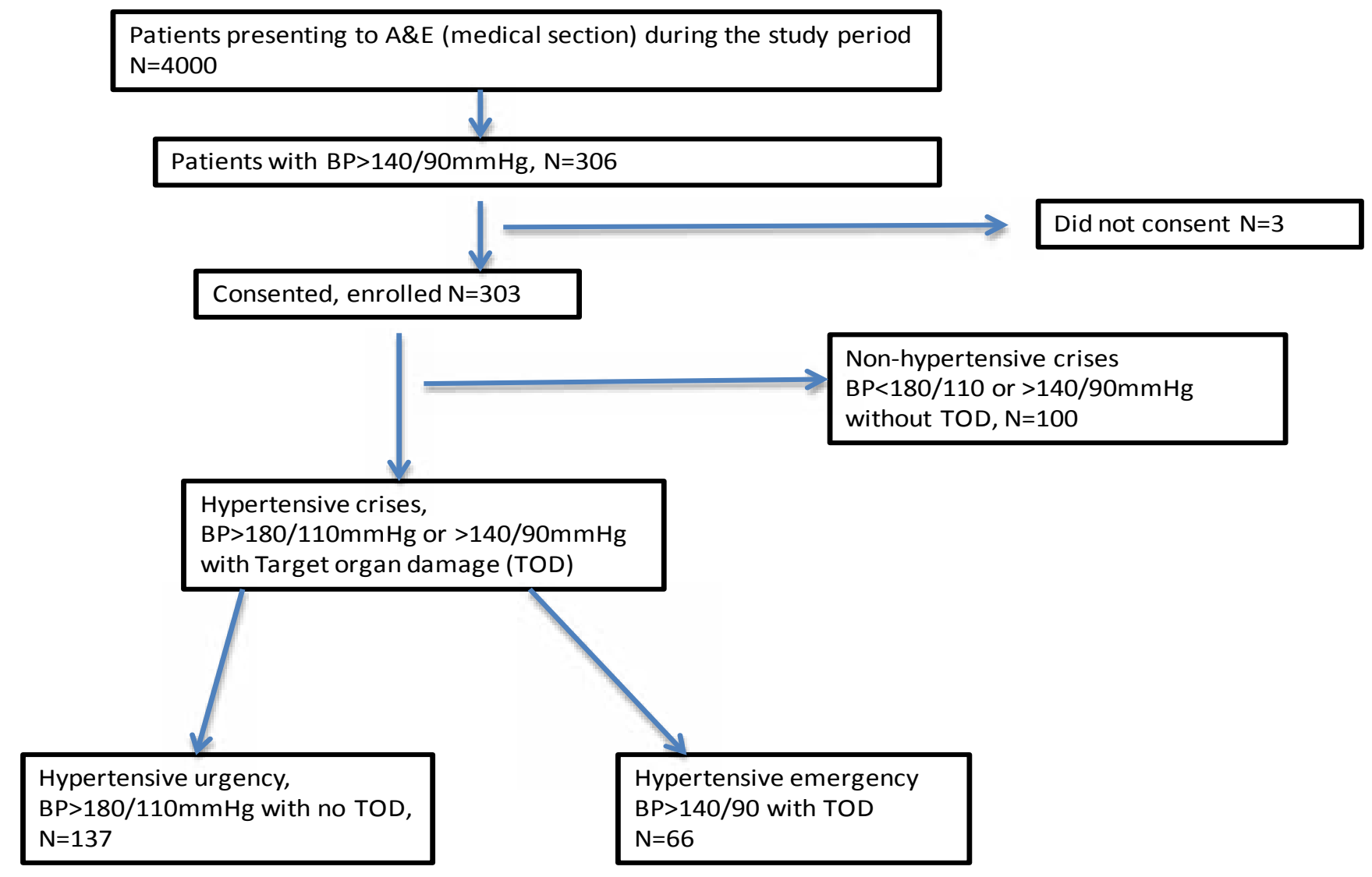

Figure 1: showing the study flow diagram

The mean age of the participants was $55.3(\mathrm{SD} \pm 17.1)$ years, with a range of $18-93$ years. About $54 \%(163 / 303)$ of those with elevated blood pressure were female. $37 \%$ of the study participants had attained primary level of education, while $22.4 \%$ had no formal education training. Majority of the study participants $(255 / 303)$ had a prior history of hypertension, $22 \%$ were diabetic, $17.5 \%$ had chronic kidney disease (CKD) while $8.6 \%$ had a history of prior stroke. Thirty-two percent $(65 / 306)$ of the participants had attained primary level of education, while $25.4 \%(51 / 306)$ had no formal education. Only $7.4 \%$ of the study participants had attained university level. Nearly half of participants were married while $25.1 \%$ were widowed. The mean age in years $( \pm S D)$ of being diagnosed hypertensive was $4.3( \pm 6.6)$ years. $16.5 \%(50 / 303)$ were newly diagnosed hypertensives.

Clinical presentations and target organ damage.

Nearly fifty-five percent $(165 / 303)$ of the study participants had an abnormal waist-hip ratio. $16 \%$ of the study participants with hypertension had abnormal low density lipoproteins (LDL). The most frequent signs of presentations among the study participants with hypertensive emergencies were neurological deficits accounting for $42.3 \%$ followed by headache $24.8 \%$, loss of consciousness $22.6 \%$, blurred vision $20.4 \%$, difficulty in breathing $14.6 \%$, dizziness $8.03 \%$ and chest pain $2.92 \%$. "See Figure 2: Clinical presentations of participants with the hypertensive emergencies." 


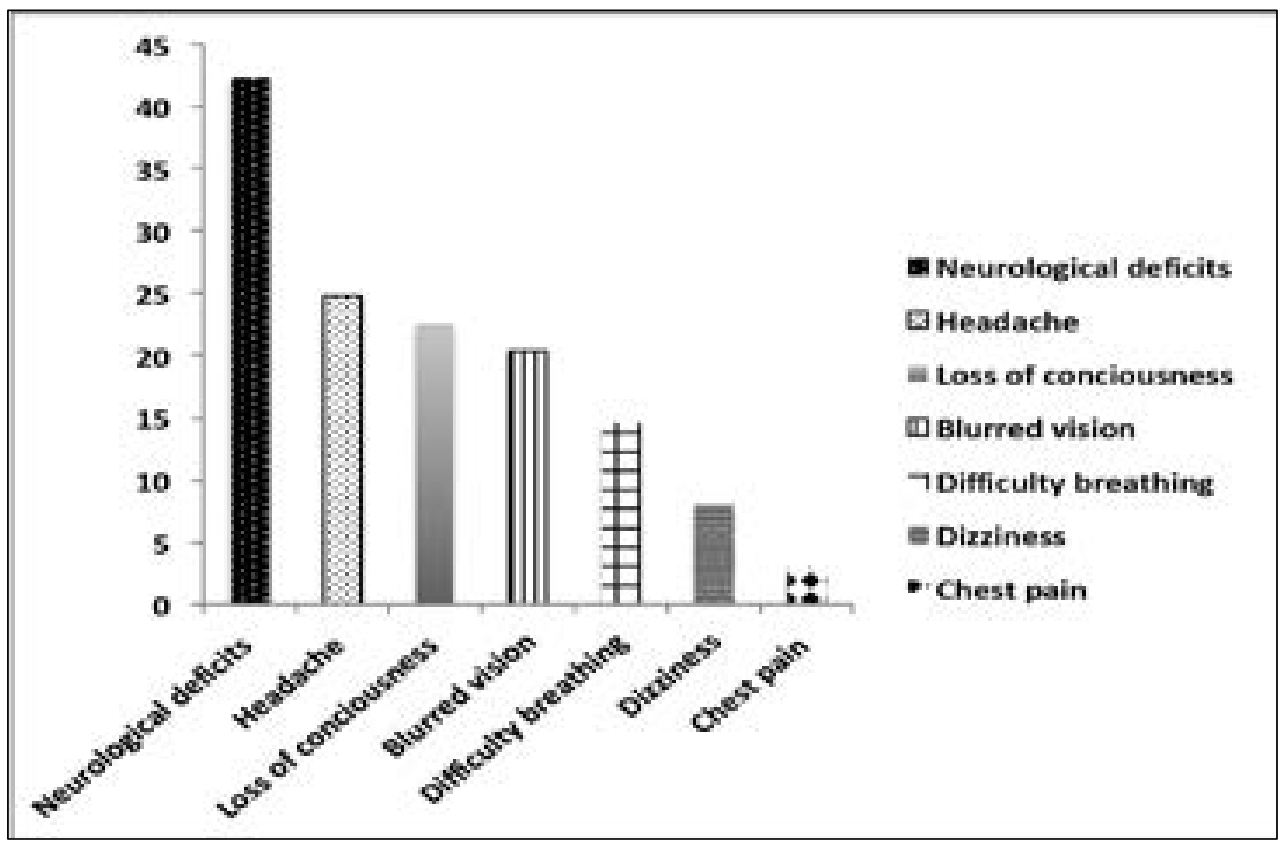

Figure 2 showing the clinical presentations of participants with the hypertensive emergencies

The types of target organ damage that were found to be associated with hypertensive emergency included acute stroke $(58 \%)$, retinopathy $(31.4 \%)$, pulmonary edema
$(13.1 \%)$, acute renal injury $8.0 \%$ and none was found to have myocardial infarction at the time of enrollment. "See Figure 3: Pattern of target organ damages of patients with hypertensive emergencies."

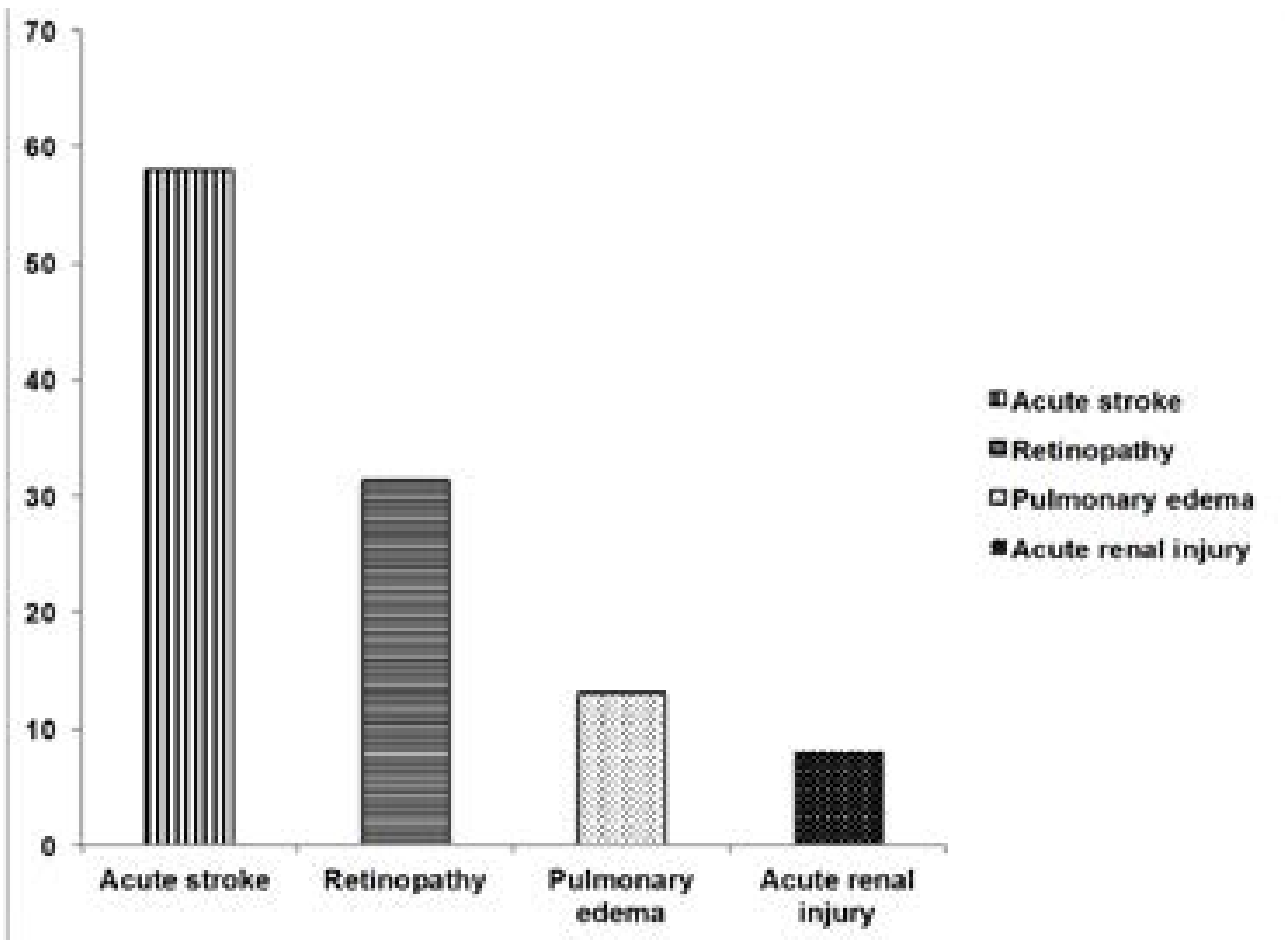

Figure 3: Pattern of target organ damages of patients with hypertensive emergencies. 
Factors associated with hypertensive crises [L10].

From bivariate analysis, the following socio-demographic and clinical factors were significantly associated with hypertensive crises. Participants who attained a primary level of education were 0.46 times less likely to get hypertensive crises compared to those that never attained any formal education, (95\% CI; $0.24-0.90)$, p -. Prior history of hypertension OR: 0.24 (95\% CI; $0.10-0.60)$. Participants who were poorly adherent to their prescribed hypertensive regimen were 52.4 times more likely to develop hypertensive crisis compared to those that had better adherence. Patients with good access to medical care OR: 0.01 (95\% CI; $000-0.07)$, and high LDL, OR: 2.21 (95\% CI; 1.05 - 4.63). "See Tables 1 and 2".

Table 1: Demographic characteristics associated with hypertensive crises.

\begin{tabular}{|c|c|c|c|c|}
\hline \multicolumn{3}{|c|}{ Demographic characteristics } & \multirow[t]{2}{*}{ OR $(95 \%$ CI $)$} & \multirow[t]{2}{*}{ P-value } \\
\hline & $\begin{array}{l}\text { Hypertensive } \\
\text { crisis } \\
\text { N }(\%)\end{array}$ & $\begin{array}{l}\text { Non-hypertensive } \\
\text { crisis } \\
\text { N }(\%)\end{array}$ & & \\
\hline Overall & $203(67.0)$ & $100(33.0)$ & & \\
\hline $\begin{array}{l}\text { Age in years } \\
<45 \\
45-65 \\
>65\end{array}$ & $\begin{array}{l}60(29.6) \\
84(41.4) \\
59(29.1)\end{array}$ & $\begin{array}{l}33(33.0) \\
42(42.0) \\
25(25.0)\end{array}$ & $\begin{array}{l}\text { Reference } \\
1.10(0.63-1.93) \\
1.30(0.69-2.44)\end{array}$ & $\begin{array}{l}0.740 \\
0.418\end{array}$ \\
\hline $\begin{array}{l}\text { Gender } \\
\text { Male } \\
\text { Female }\end{array}$ & $\begin{array}{l}95(46.8) \\
108(53.2)\end{array}$ & $\begin{array}{l}45(45.0) \\
55(55.0)\end{array}$ & $\begin{array}{l}\text { Reference } \\
0.93(0.58-1.50)\end{array}$ & 0.768 \\
\hline $\begin{array}{l}\text { Education level } \\
\text { None } \\
\text { Primary } \\
\text { Secondary } \\
\text { Trade-school } \\
\text { College/University }\end{array}$ & $\begin{array}{l}51(25.4) \\
65(32.0) \\
50(24.6) \\
22(10.8) \\
15(7.4)\end{array}$ & $\begin{array}{l}17(17.0) \\
47(47.0) \\
11(11.0) \\
15(15.0) \\
10(10.0)\end{array}$ & $\begin{array}{l}\text { Reference } \\
0.46(0.24-0.90) \\
1.52(0.65-3.56) \\
0.49(0.21-1.15) \\
0.50(0.19-1.32)\end{array}$ & $\begin{array}{l}\mathbf{0 . 0 2 2} \\
0.340 \\
0.101 \\
0.161\end{array}$ \\
\hline $\begin{array}{l}\text { Currently } \\
\text { employed } \\
\text { No } \\
\text { Yes }\end{array}$ & $\begin{array}{l}130(64.0) \\
73(36.0)\end{array}$ & $\begin{array}{l}62(62.0) \\
38(36.0)\end{array}$ & $\begin{array}{l}\text { Reference } \\
0.92(0.56-1.50)\end{array}$ & 0.729 \\
\hline $\begin{array}{l}\text { Marital status } \\
\text { Married } \\
\text { Never married } \\
\text { Widowed } \\
\text { Separated }\end{array}$ & $\begin{array}{l}109(53.7) \\
12(5.9) \\
51(25.1) \\
31(15.3)\end{array}$ & $\begin{array}{l}54(54.0) \\
8(8.0) \\
26(26.0) \\
12(12.0)\end{array}$ & $\begin{array}{l}\text { Reference } \\
0.74(0.29-1.93) \\
0.97(0.55-1.73) \\
1.28(0.61-2.69)\end{array}$ & $\begin{array}{l}0.541 \\
0.922 \\
0.515\end{array}$ \\
\hline
\end{tabular}


Table 2: Clinical factors associated with hypertensive crises.

\begin{tabular}{|c|c|c|c|c|}
\hline Clinical factor & $\begin{array}{l}\text { Hypertensive } \\
\text { Crisis N (\%) }\end{array}$ & $\begin{array}{l}\text { Non-Hypertensive } \\
\text { crisis N (\%) }\end{array}$ & OR (95\% CI) & P-value \\
\hline $\begin{array}{l}\text { Waist/hip ratio } \\
\text { Abnormal }\end{array}$ & $106(52.2)$ & $59(59.0)$ & $0.76(0.47-1.23)$ & 0.265 \\
\hline $\begin{array}{l}\text { Hypertension } \\
\text { Yes }\end{array}$ & $161(79.3)$ & $94(94.0)$ & $0.24(0.10-0.60)$ & 0.002 \\
\hline $\begin{array}{l}\text { Diabetes mellitus } \\
\text { Yes }\end{array}$ & $38(18.7)$ & $28(28.0)$ & $0.59(0.38-1.04)$ & 0.067 \\
\hline $\begin{array}{l}\text { Stroke } \\
\text { Yes }\end{array}$ & $19(9.4)$ & $7(7.0)$ & $1.37(0.56-3.38)$ & 0.492 \\
\hline $\begin{array}{l}\text { Chronic kidney disease } \\
\text { Yes }\end{array}$ & $34(16.8)$ & $19(19.0)$ & $0.86(0.46-1.60)$ & 0.628 \\
\hline $\begin{array}{l}\text { Self-reported adherence } \\
\text { Poor }(\leq 3 / 5)\end{array}$ & $192(94.6)$ & $25(25.0)$ & $52.4(24.5-111.7)$ & $<0.001$ \\
\hline $\begin{array}{l}\text { Access to medical care } \\
\text { Never } \\
\text { Sometimes } \\
\text { Often } \\
\text { Always } \\
\text { No answer }\end{array}$ & $\begin{array}{l}18(8.9) \\
126(62.1) \\
7(3.5) \\
1(0.5) \\
51(25.1)\end{array}$ & $\begin{array}{l}4(4.0) \\
23(23.0) \\
34(34.0) \\
32(32.0) \\
7(7.0)\end{array}$ & $\begin{array}{l}\text { Reference } \\
1.22(0.38-3.93) \\
0.05(0.01-0.18) \\
0.01(0.00-0.07) \\
1.62(1.11-6.19)\end{array}$ & $\begin{array}{l}<\mathbf{0 . 0 0 1} \\
0.742 \\
<\mathbf{0 . 0 0 1} \\
<\mathbf{0 . 0 0 1} \\
0.481\end{array}$ \\
\hline $\begin{array}{l}\text { Current/past alcohol use } \\
\text { Yes }\end{array}$ & $98(48.3)$ & $43(43.0)$ & $1.24(0.76-2.00)$ & 0.387 \\
\hline $\begin{array}{l}\text { Smoking } \\
\text { Yes }\end{array}$ & $36(17.8)$ & $14(14.0)$ & $1.32(0.68-2.59)$ & 0.411 \\
\hline $\begin{array}{l}\text { Ever used contraceptives } \\
\text { Yes }\end{array}$ & $22(20.4)$ & $12(21.8)$ & $0.98(0.47-2.06)$ & 0.964 \\
\hline \multicolumn{5}{|l|}{ Cholesterols } \\
\hline $\begin{array}{l}\text { LDL } \\
>4.1\end{array}$ & $40(19.7)$ & $10(10.0)$ & $2.21(1.05-4.63)$ & 0.036 \\
\hline $\begin{array}{l}\text { HDL } \ddagger \\
<0.9 \text { or }<1\end{array}$ & $119(58.6)$ & $55(55.0)$ & $1.16(0.72-1.88)$ & 0.549 \\
\hline
\end{tabular}

At multivariate analysis a model building was done using likelihood ratio test to obtain adjusted estimates, poor adherence to prescribed hypertensive drug regimens OR $52.4(24.5$ - 111.7) and better access to medical care at odds ratios of $0.05(0.01-0.18)$ were significantly associated with hypertensive crisis. Level of education was not associated with hypertensive crises. The factors associated with hypertensive crises at multivariate analysis are shown in "Table 3". 
Table 3: Factors associated with hypertensive crises at multivariate analysis.

\begin{tabular}{|c|c|c|c|c|}
\hline & \multicolumn{2}{|c|}{ Unadjusted estimates } & \multicolumn{2}{|c|}{ Adjusted estimates } \\
\hline & $\begin{array}{l}\text { Odds Ratio } \dagger \\
95 \% \text { CI }\end{array}$ & P value & $\begin{array}{l}\text { Odds Ratio } \uparrow \\
95 \% \text { CI }\end{array}$ & P value \\
\hline $\begin{array}{l}\text { Adherence } \\
\text { Good } \\
\text { Poor }\end{array}$ & $\begin{array}{l}\text { Reference } \\
52.4 \quad(24.5 \quad- \\
111.7)\end{array}$ & $<0.001$ & \begin{tabular}{l}
\multicolumn{3}{l}{$\begin{array}{l}\text { Reference } \\
25.13 \quad(9.16 \\
68.92)\end{array} \quad-$}
\end{tabular} & $<0.001$ \\
\hline $\begin{array}{l}\text { Access to medical care } \\
\text { Never } \\
\text { Sometimes } \\
\text { Often } \\
\text { Always } \\
\text { No answer }\end{array}$ & $\begin{array}{l}\text { Reference } \\
1.22(0.38-3.93) \\
0.05(0.01-0.18) \\
0.01(0.00-0.07) \\
1.62(1.11-6.19)\end{array}$ & $\begin{array}{l}0.742 \\
<0.001 \\
<0.001 \\
0.481\end{array}$ & $\begin{array}{l}\text { Reference } \\
1.94(0.52-7.24) \\
0.27(0.05-1.46) \\
0.04(0.00-0.53) \\
0.99(0.23-4.18)\end{array}$ & $\begin{array}{l}0.325 \\
0.129 \\
0.014 \\
0.987\end{array}$ \\
\hline $\begin{array}{l}\text { Education level } \\
\text { None } \\
\text { Primary } \\
\text { Secondary } \\
\text { Trade-school } \\
\text { College/University }\end{array}$ & $\begin{array}{l}\text { Reference } \\
0.46(0.24-0.90) \\
1.52(0.65-3.56) \\
0.49(0.21-1.15) \\
0.50(0.19-1.32)\end{array}$ & $\begin{array}{l}\mathbf{0 . 0 2 2} \\
0.340 \\
0.101 \\
0.161\end{array}$ & $\begin{array}{l}\text { Reference } \\
0.42(0.15-1.18) \\
2.83(0.71-11.39) \\
0.81(0.19-3.55) \\
1.20(0.27-5.42)\end{array}$ & $\begin{array}{l}0.098 \\
0.142 \\
0.781 \\
0.809\end{array}$ \\
\hline
\end{tabular}

\section{Discussion}

The study set out to determine the prevalence, patterns and factors associated with hypertensive crises in $\mathrm{Mu}-$ lago emergency department. The prevalence of hypertensive crises was $5.1 \%$, with a $2: 1$ ratio of hypertensive emergencies to hypertensive urgencies. The findings of this study are slightly higher than the prevalence reported from previous studies in Africa by Ellenge et al. and Garcia et al. which reported prevalence's of $4 \%$ to $4.3 \%$ respectively ${ }^{16,17}$. This might be due to the differences in the study settings, Mulago is the National Referral Hospital and tends to receive complex patients from all-over Uganda. Patients with hypertensive emergencies might be referred for specialized care and investigations.

In our study, low rate of compliance to prescribed hypertensive drug regimens was independently associated with hypertensive emergency. This is in agreement with other studies that also found that non adherence to prescribed medication was statistically significant to developing a hypertensive emergency. Several studies in Africa, have reported poor compliance to anti-hypertensive treatment and poor access to health facilities ${ }^{18-20}$. This likely contributes to the uncontrolled hypertension among people in low income countries, therefore patients are likely to present with complications.

History of hypertension was found to be significantly associated with hypertensive emergency at bivariate analysis although not at multivariate analysis. This is in contrast to multiple studies that have consistently found prior hypertension significantly associated with hypertensive emergencies $^{16,17,21}$. This could be an effect from preference of other factors chosen to adjust it for.

Acute stroke (both hemorrhagic and ischemic stroke) was the most common form of presentation in our population, in agreement with various studies ${ }^{16,17}$. Based on the data of our study on the clinical manifestation of hypertensive emergency in the accident and emergency medical services, cerebrovascular lesions were the most common, followed by retinopathy and acute pulmonary edema.

\section{Conclusion}

This pioneering study on the prevalence of hypertensive crises, shows their importance in medical emergencies and the most frequent types of target-organ lesions. Targeted measures are needed to address and prevent these emergencies from occurring.

\section{Study limitations}

This study had the following limitations: recall bias for patients or guardians, especially drug compliance. This was a cross-sectional study hence difficult to determine the cause-effect relationship. The investigations undertaken for the patients such as the brain CT scan and cardiac markers were guided by clinical presentation due to financial limitations, this might have underestimated the 
target organ damage. However, the study provides an insight into the hypertensive emergencies we face in our setting and developing targeted interventions is needed.

\section{List of abbreviations}

A/E - Accident and Emergency

CVD - Cardiovascular disease

HDL - High density lipoprotein

LDL - Low density lipoprotein

\section{Declarations}

Ethics approval and consent to participate in this study

Written informed consent was obtained from the next of kin / legal representatives for all study participants. The next of kin/eligible participants were approached by the study team for consent to participate in the study. Information about the study, its potential risks and benefits to the patients were elaborated to the patients/relatives in simple and concise language. Approval for conducting the study in the two hospitals was provided from the School of Medicine, Research and Ethics Committee (SOMREC) of Makerere University College of Health Sciences (Ref no -2015-130) and Uganda National council of Science and Technology.

\section{Consent for publication}

"Not applicable"

\section{Availability of data and material}

All data generated or analyzed during this study are included in this published article

\section{Competing interests}

The authors declare that they have no competing interests.

\section{Funding}

This study was supported by the National Institute of Neurological Disorders and Stroke of the National Institute of Health under MEPI - Neurology linked award number R25NS080968. EO receives support from the DELTAS Africa Initiative grant \# DEL-15-011 to THRiVE 2. The DELTAS Africa Initiative is a funding scheme of the Accelerating Excellence in Science Africa initiative (AESA) with funding from the Wellcome Trust grant \# 107742/Z/15/Z and the UK Government. The funders had no role in the study design, collection, analysis, and interpretation of data and in writing the manuscript.

\section{Authors' contribution}

IN, JN, MK and EO conceived the study. IN and JN saw the patients. IN, JN, EO, MK did the analysis and wrote the first draft, while EK and MS critically read through the manuscript. IN, MK, JN, EO, MS and EK revised the manuscript for important intellectual content. All authors discussed the results and commented on the manuscript. All authors read and approved the final manuscript.

\section{Acknowlegdements}

We also thank our study subjects for participating in this study. The Mulago hospital, department of medicine, accident and emergency unit for providing a conducive environment for our research activities. We also greatly appreciate the support from Dr. Kalinzi M (Ophthalmology, resident) as well as Dr. Ntende J (consultant ophthalmologist) for their assistance during fundus examination.

\section{References}

1. World Health Organization. Global Status Report on Non-Communicable Diseases 2010. World Health Organisation, Geneva; 2011.

2. Opie LH, Seedat YK. Hypertension in sub-Saharan African populations. Circulation. 2005;112(23):3562-8.

3. Rosamond W, Flegal K, Furie K, Go A, Greenlund K, Haase N, et al. Heart disease and stroke statistics--2008 update: a report from the American Heart Association Statistics Committee and Stroke Statistics Sub-committee. Circulation. 2008;117(4):e25-146.

4. Pereira M, Lunet N, Azevedo A, Barros H. Differences in prevalence, awareness, treatment and control of hypertension between developing and developed countries. Journal of Hypertension. 2009;27(5):963-75.

5. Twagirumukiza M, De Bacquer D, Kips JG, de Backer G, Vander Stichele R, Van Bortel LM. Current and projected prevalence of arterial hypertension in sub-Saharan Africa by sex, age and habitat: an estimate from population studies. Journal of Hypertension. 2011;29(7):1243-52.

6. Hendriks ME, Wit FW, Roos MT, Brewster LM, Akande TM, de Beer IH, et al. Hypertension in sub-Saharan Africa: cross-sectional surveys in four rural and urban communities. PloS One. 2012;7(3):e32638.

7. Kayima J, Wanyenze RK, Katamba A, Leontsini E, 
Nuwaha F. Hypertension awareness, treatment and control in Africa: a systematic review. BMC cardiovascular disorders. 2013;13(1):1.

8. Maher D, Waswa L, Baisley K, Karabarinde A, Unwin $\mathrm{N}$. Epidemiology of hypertension in low-income countries: a cross-sectional population-based survey in rural Uganda. Journal of Hypertension. 2011;29(6):1061-8.

9. Wamala JF, Karyabakabo Z, Ndungutse D, Guwatudde D. Prevalence factors associated with hypertension in Rukungiri district, Uganda-a community-based study. African health sciences. 2009;9(3).

10. Chobanian AV, Bakris GL, Black HR, Cushman WC, Green LA, Izzo JL, Jr., et al. The Seventh Report of the Joint National Committee on Prevention, Detection, Evaluation, and Treatment of High Blood Pressure: the JNC 7 report. JAMA. 2003;289(19):2560-72.

11. Ault MJ, Ellrodt AG. Pathophysiological events leading to the end-organ effects of acute hypertension. Am J Emerg Med. 1985;3(6 Suppl):10-5.

12. Vidt GD, Gifford RW, Jr. A compendium for the treatment of hypertensive emergencies. Cleve Clin Q. 1984;51(2):421-30.

13. Lorenzo C, Williams K, Hunt KJ, Haffner SM. The National Cholesterol Education Program-Adult Treatment Panel III, International Diabetes Federation, and World Health Organization definitions of the metabolic syndrome as predictors of incident cardiovascular disease and diabetes. Diabetes care. 2007;30(1):8-13.

14. Keith NM WH, Barker NW, . Some different types of essential hypertension: their course and prognosis. Am J Med Sci. 1974; 268:336-45 PubMed .

15. Expert Panel on Detection E, and Treatment of High Blood Cholesterol in Adults, . Executive summary of the third report of the national cholesterol education program (NCEP) expert panel on detection, evaluation, and treatment of high blood cholesterol in adults (adult treatment panel III). JAMA. 2001;285:2486-97.

16. Ellenga MB, Gombet TR, Mahoungou GK, Otiobanda GF, Ossou NP, Ikama MS, et al.[Hypertensive emergencies at the University Hospital Center in Brazzaville, Congo]. Med Trop. (Mars). 2011;71(1):97-8.

17. Garcia GM, Miudo V, Manuel Lopes Cda G, Vas- suelela Gomes J. Characterization of patients aged 45 or under admitted with hypertensive emergencies in the Hospital do Prenda. Rev Port Cardiol. 2014;33(1):19-25.

18. Babiker FA, Elkhalifa LA, Moukhyer ME. Awareness of hypertension and factors associated with uncontrolled hypertension in Sudanese adults. Cardiovasc J Afr. 2013;24(6):208-12.

19. Mugwano I, Kaddumukasa M, Mugenyi L, Kayima J, Ddumba E, Sajatovic M, et al. Poor drug adherence and lack of awareness of hypertension among hypertensive stroke patients in Kampala, Uganda: a cross sectional study. BMC Res Notes. 2016;9:3.

20. Lulebo AM, Mutombo PB, Mapatano MA, Mafuta EM, Kayembe PK, Ntumba LT, et al. Predictors of non-adherence to antihypertensive medication in Kinshasa, Democratic Republic of Congo: a cross-sectional study. BMC Res Notes. 2015;8:526.

21. Cappuccio FP, Micah FB, Emmett L, Kerry SM, Antwi S, Martin-Peprah R, et al. Prevalence, detection, management, and control of hypertension in Ashanti, West Africa. Hypertension. 2004;43(5):1017-22.

22. Guwatudde D, Mutungi G, Wesonga R, Kajjura R, Kasule H, J Muwonge (2015). The Epidemiology of Hypertension in Uganda: Findings from the National Non-Communicable Diseases Risk Factor Survey. PLoS One, 10(9), e0138991.

23. James PA, Oparil S, Carter BL, Cushman, W. C., Dennison-Himmelfarb, C., Handler, J., ... \& Smith, S. C. (2014). 2014 evidence-based guideline for the management of high blood pressure in adults: report from the panel members appointed to the Eighth Joint National Committee (JNC 8). JAMA, 311(5), 507-520.

24. Shea S, et al., Predisposing factors for severe, uncontrolled hypertension in an inner-city minority population. New England Journal of Medicine, 1992. 327(11): p. 776-781. 25. Zampaglione BPC., Marchisio M, et al., Hypertensive urgencies and emergencies. Prevalence and clinical presentation. Hypertension, 1996. 27: p. 144-147.

26. Giles TD, Materson BJ, Cohn, JN, Kostis JB. (2009). Definition and classification of hypertension: an update. The Journal of Clinical Hypertension, 11(11), 611-614.

27. Rajappa M, Sharma A. (2005). Biomarkers of cardiac injury: an update. Angiology, 56(6), 677-691. 